\title{
Rendimento do milho doce e verde para consumo "in natura" cultivados no Tocantins
}

\author{
The yield of sweet and green corn consumed "in natura" (unprocessed) cultivated in Tocantins \\ Rendimiento de maíz dulce y verde para consumo "in natura" cultivado en Tocantins
}

Recebido: 18/02/2021 | Revisado: 26/02/2021 | Aceito: 01/03/2021 | Publicado: 08/03/2021

Ila Raquel Mello Cardoso

ORCID: https://orcid.org/0000-0002-3481-0090

Universidade Federal do Tocantins, Brasil

E-mail: ila.cardoso@catolica-to.edu.br

Marcio Eckardt

ORCID: https://orcid.org/0000-0002-6756-9053

Universidade Federal do Tocantins, Brasil

E-mail:adm1marcio@gmail.com

Flávio Sérgio Afférri

ORCID: https://orcid.org/0000-0002-0819-4108

Universidade Federal do Tocantins, Brasil

E-mail: flavioafferri@gmail.com

Glêndara Aparecida de Souza Martins

ORCID: https://orcid.org/0000-0002-3813-1028

Universidade Federal do Tocantins, Brasil

E-mail: glendarasouza@mail.uft.edu.br

Joênes Mucci Peluzio

ORCID: https://orcid.org/0000-0002-9336-2072

Universidade Federal do Tocantins, Brasil

E-mail: joenesp@mail.uft.edu.br

Juliana Santos Moura

ORCID: https://orcid.org/0000-0003-2117-394X

Instituto Federal do Tocantins, Brasil

E-mail: juliana.moura@ifto.edu.br

Polliana Cristina de Lima Santos

ORCID: https://orcid.org/0000-0002-2536-1019 Instituto Federal do Tocantins, Brasil E-mail: pollycrispollycris@gmail.com

Lourena Jacy Fonseca Borges

ORCID: https://orcid.org/0000-0003-1326-0875 Instituto Federal do Tocantins, Brasil E-mail: lourennajacy@gmail.com

Rafaela Soares Biase

ORCID: https://orcid.org/0000-0001-5648-4524 Instituto Federal do Tocantins, Brasil E-mail: rafahbiase@gmail.com

\begin{abstract}
Resumo
O milho (Zea mays L.) pertence à família Poaceae, se destaca pela grande diversidade genética, adaptando-se em diversos climas. Este estudo tem como objetivo estudar o rendimento do milho verde e milho doce cultivadas no Tocantins. Os experimentos foram realizado na Universidade Federal do Tocantins - UFT, Campus de Palmas e Instituto Federal do Tocantins - IFTO, Campus de Paraíso, onde foram plantados 4 cultivares de milho ( C1, C2 e C3 de milho verde comum e $\mathrm{C} 4$ de milho doce), sobre diferentes ambientes, níveis de adubação e épocas de semeadura. Os rendimentos de grãos verdes da C4 foram semelhantes $(\mathrm{p}<0,05)$, pelo teste de Scott-Knott, com as C1 e C3 nos ambientes 2 e 4. Já nos ambientes 1 a $\mathrm{C} 1$ assemelhou-se com a C3, e no ambiente 3 a $\mathrm{C} 3$ teve um maior rendimento de $77 \%$. Observa-se que o milho doce cultivado em Palmas - TO apresentou um rendimento de grãos verdes de $60 \%$, semelhante a $\mathrm{C} 1$, desta forma nota-se que mesmo em condições climáticas distintas e genótipos de milho diferentes, o milho doce apresentou viabilidade produtiva semelhante ao milho verde. Conclui-se que é importante estudar o rendimento dos grãos de milho doce e verde, pois influenciam na produtividade.
\end{abstract}

Palavras-chave: Zea mays L.; Adubação nitrogenada; Cereais. 


\begin{abstract}
Corn (Zea mays L.) belongs to the Poaceae family, stands out for its great genetic diversity, adapting in different climates. This study aims to study the yield of green and sweet corn grown in Tocantins. The experiments were carried out at the Federal University of Tocantins - UFT, Palmas's Campus and Federal Institute of Tocantins - IFTO, Paraiso's Campus, where 4 corn cultivars were planted (C1, C2 and C3 of common green corn and C4 of sweet corn), on different environments, fertilization levels and sowing times. The yield green grains of C4 were similar ( $\mathrm{p}<0.05)$, by the Scott-Knott test, with $\mathrm{C} 1$ and $\mathrm{C} 3$ in environments 2 and 4 . In environment $1, \mathrm{C} 1$ was similar to $\mathrm{C} 3$, and environment 3 to $\mathrm{C} 3$ had higher yield of $77 \%$. It is observed that sweet corn grown in Palmas - TO presented a yield green grain of $60 \%$, similar to $\mathrm{C} 1$, it is noted that even under different climatic conditions and different corn genotypes, sweet corn showing similar productive viability to green corn. It is concluded that it is important to study the yield of sweet and green corn grains, as they influence productivity.
\end{abstract}

Keywords: Zea mays L.; Nitrogen fertilization; Cereals.

\title{
Resumen
}

El maíz (Zea mays L.) pertenece a la familia Poaceae, destaca por su gran diversidad genética, adaptándose en diferentes climas. Este estudio tiene como objetivo estudiar el rendimiento del maíz verde y dulce cultivado en Tocantins. Los experimentos se realizaron en la Universidad Federal de Tocantins - UFT, Campus de Palmas e Instituto Federal de Tocantins - IFTO, Campus de Paraíso, donde se sembraron 4 cultivares de maíz (C1, C2 y C3 de maíz verde común y $\mathrm{C} 4$ de maíz dulce), en diferentes ambientes, niveles de fertilización y tiempos de siembra. Los rendimientos de granos verdes de C4 fueron similares ( $\mathrm{p}<0.05$ ), según la prueba de Scott-Knott, con C1 y C3 en los ambientes 2 y 4 . En los ambientes 1 a C1 fue similar a C3, y en el ambiente 3 a C3 tuvo un rendimiento superior del $77 \%$. Se observa que el maíz dulce cultivado en Palmas - TO mostró un rendimiento de grano verde de 60\%, similar al $\mathrm{C} 1$, por lo que se observa que aún bajo diferentes condiciones climáticas y diferentes genotipos de maíz, el maíz dulce mostró una viabilidad productiva similar al maíz verde. Concluimos que es importante estudiar el rendimiento de los granos de maíz dulce y verde, ya que influyen en la productividad.

Palabras clave: Zea mays L.; Fertilización con nitrógeno; Cereales.

\section{Introdução}

O milho (Zea mays L.) é uma planta da família Poaceae, originária da América Central, com grande capacidade de adaptação a diversos climas desde regiões úmidas a regiões secas, devido a uma diversidade genética dentro da espécie. Os grãos do milho possuem a coloração amarela ou branca, podendo variar desde o preto até o vermelho. O peso médio do grão é de 250 a 300mg, tendo a seguinte composição em base seca: 72\% de amido, 7 a 14\%\% de proteínas, 9\% de fibra (a maioria resíduo detergente neutro) e 2,5 a 5\% de óleo (Santos, 2018).

O milho (Zea mays L.) se destaca como sendo um dos principais grãos de cereais cultivados em todo o mundo, estando presente na dieta básica nas pessoas da região da América Latina, Ásia e África. O consumo dos grãos de milho variam desde a forma in natura, até os processados, como por exemplo, milho em conserva, farinha de milho, amido de milho, cereais matinais e também é usado para alimentação animal (Giordano et al., 2018).

No Brasil é uma tradição o plantio do milho verde, mesmo com a disponibilidade reduzidas de sementes para produção de milho verde in natura, esta atividade se destaca em pequenas e médias propriedades com áreas entre 1 e 10 ha (Nascimento, 2017).

Segundo a Companhia Nacional de Abastecimento [CONAB] (2020), o Brasil teve uma produção de milho na temporada 2019/20 em torno de 18,5 milhões de hectares plantados com uma produção de 102,3 milhões de toneladas, neste período observou-se um aumento das exportações, processo contribuído pelo crescimento da aplicabilidade deste cereal na produção de etanol e no aumento do confinamento de animais.

Segundo CONAB (2020), a Região Norte-Nordeste do Brasil aumentou 9,6\% da área de produção de milho, em relação ao ano anterior, totalizando uma área de 1.313,7 mil hectares, atingindo desta maneira uma produção de 5.570,8 mil toneladas, contribuindo para o aumento de 20,9\% da produção para o ano de 2020. No Estado do Tocantins as lavouras de milho para a primeira safra do período 2019/20 obtiveram resultados produtivos equivalente a 260 mil toneladas (CONAB, 2020). O Estado do Tocantins representa uma nova fronteira agrícola para a produção de milho, destacando-se com o aumento 
da produtividade, para isso é necessário escolher a correta época de plantio e a seleção de cultivares a serem plantadas em cada região, segundo Empresa Brasileira de Pesquisa Agropecuária [Embrapa] (2016). O plantio de milho no Tocantins ocorre entre os meses de novembro e fevereiro, sendo que o milho safrinha deve ser plantado ainda no período do verão, até a primeira quinzena do mês de fevereiro, dependendo do período chuvoso.

A produtividade do milho também depende da eficiência de canalização de carbono e nitrogênio para os grãos e da transformação desses elementos em compostos de reserva. Ainda, a escassez de nitrogênio influencia diretamente na capacidade fotossintética das plantas. (Martin et al., 2011). Considera-se que em áreas temperadas, a semeadura precoce contribui para o aumento do rendimento de grão, isso ocorre devido a maior eficiência do uso da radiação durante o processo de amadurecimento dos grãos. Desta forma observa-se que o período de semeadura é um dos fatores correlacionados para a melhoria da produtividade do milho e na produção de compostos bioativos, como a capacidade antioxidante, conteúdo de ácidos fenólicos, carotenóides e antocianinas de grãos (Couto et al., 2017).

Segundo Couto et al. (2017), a adubação nitrogenada realizada no plantio do milho também contribui para maior produtividade e influencia na produção de bioativos presentes na farinha de milho integral, tais como: fenólicos totais ligados à parede celular e as duas xantofilas presentes nos grãos de milho. Diante dos resultados observados neste estudo, nota-se o rendimento dos grãos sofre efeitos significativos com a nitrogênio na adubação e com período de semeadura.

O milho (Zea mays L.) possui uma aplicabilidade não apenas associada a alimentação humana e animal, mas também é aplicado em forragem, energia e materiais industriais. Para as diversas maneiras de se utilizar os grãos de milho há características agronômicas relevantes, tais como o número e peso de grãos (determinam o rendimento de grãos por planta), também é necessário avaliar os fatores genéticos, fisiológicos e ambientais (Xiaotong et al., 2018).

No Brasil o consumo de milho verde é uma tradição, sendo comercializado para consumo "in natura" ou processado, tais como: pamonha, curau, suco, bolo, sorvete, farinhas entre outros. Já o milho doce possui uma grande diversidade de aplicações, podendo ser utilizado em conservas, congelados na forma de espigas ou grãos, desidratados e "baby corn" ou minimilho (colhido antes da polinização) (Fritsche-neto et al., 2012). Desta forma este estudo tem como objetivo estudar e comparar o rendimento das cultivares de milho verde e de milho doce para o consumo "in natura", cultivadas no estado do Tocantins, pois há poucos estudos sobre o cultivo de milho doce na Região Norte do Brasil.

\section{Metodologia}

Este trabalho baseia-se em um método hipotético-dedutivo, pois formulou-se hipóteses para a solução de um problema, sendo que foi realizado um estudo prático e experimental (pesquisa prática), a abordagem do problema foi realizada de forma quantitativa (utilização de informações numéricas e construção de tabelas demonstrativas) (Gil, 1994). Para a realização deste estudo foram semeados três cultivares de milho verde e uma cultivar de milho doce no Centro Agrotecnológico da Universidade Federal do Tocantins - UFT, Campus de Palmas (220 m de altitude, $10^{\circ} 45^{\prime}$ de latitude Sul e 47 $14^{\prime}$ de longitude Oeste), em solo do tipo Latossolo Vermelho Amarelo Distrófico; e no Instituto Federal do Tocantins IFTO, Campus de Paraíso (387 m de altitude, $10^{\circ} 15^{\prime}$ 'de latitude Sul e 4853' de longitude Oeste), em solo do tipo Latossolo Vermelho Distrófico.

Utilizaram-se cultivares comerciais e estas foram adquiridas no comércio local. As cultivares de milho plantadas foram: C1 (milho híbrido simples, com graus dia (GD) utilizado na produção de milho verde "in natura", C2 (variedade, aplicado na produção de milho verde "in natura", C3 (hibrido triplo, utilizado na produção de milho verde "in natura") e C4 (milho doce híbrido simples), aplicado para a produção de milho em conserva e consumo "in natura". 
Os atributos químicos do solo (0 a $20 \mathrm{~cm}$ ), da área plantada, da cidade de Palmas - TO foram: pH em Cacl2 = 5,92; V (saturação bases) $=54,02 \%$ e CTC $=3,48$; e para a área de Paraíso do Tocantins foram: pH em Cacl2 = 6,1, V (saturação bases $)=76,43 \%$ e CTC $=5,94$; por meio destes dados realizou-se um tratamento prévio do solo, do tipo convencional, com uma gradagem e nivelamento da área. A adubação de pré-semeadura foi realizada manualmente, utilizando $400 \mathrm{~kg}$ ha-1 de NPK de 8-28-16 + 0,3\% Zn, para todos os ensaios. A semeadura foi realizada com o intuito de se obter 40.000 plantas por hectares.

O delineamento experimental foi em blocos casualizados no esquema de parcelas subdivididas, com 3 repetições, sendo a parcela representada em $\mathrm{N}$ na adubação em dois níveis de $40 \mathrm{~kg} \mathrm{ha}^{-1}$ e $120 \mathrm{~kg} \mathrm{ha}^{-1}$ e a sub-parcela representa as cultivares de milho verde e milho doce, totalizando combinações entre cultivares e nitrogênio. Cada parcela experimental foi composta por três linhas de cinco metros lineares cada, com espaçamento de $0,8 \mathrm{~m}$ entre linhas.

Os 4 experimentos foram realizados em 4 ambientes (ambiente 1 = plantio em dezembro de 2018 em Palmas - TO; ambiente 2 = plantio em dezembro de 2018 em Paraiso - TO; ambiente 3 = plantio em janeiro de 2019 em Palmas - TO e ambiente 4 = plantio em janeiro de 2019 em Paraiso - TO).

A adubação em cobertura foi realizada manualmente e em dose única, nas plantas que se encontravam no estágio com quatro folhas completamente abertas, utilizaram-se níveis de $40 \mathrm{~kg} \mathrm{ha}^{-1} \mathrm{e} 120 \mathrm{~kg} \mathrm{ha}^{-1} \mathrm{de} \mathrm{N}$ na forma de sulfato de amônio.

Para o controle fitossanitário contra as doenças, as pragas e as plantas daninhas aplicaram-se os tratos culturais, de acordo com as recomendações técnicas de cada cultura.

Para avaliar o rendimento das cultivares de milho verde e doce, colheram-se as espigas no estágio de milho verde, considerado milho para consumo in natura (ponto de milho verde) com umidade dos grãos entre 70 a $80 \%$, o qual realizou as seguintes avaliações: MVESP (Massa verde média de espiga sem palha - g), CEVSP ( Comprimento médio de espiga verde sem palha - cm), DEVSP ( Diâmetro médio de espiga verde sem palha - cm), MGV ( Massa verde de grãos média da espiga g) e RG ( Rendimento de grãos verdes na espiga = 100 x (MGV/MVESP - \%). Nestas etapas utilizou-se paquímetro manual para medir o diâmetro $(\mathrm{mm})$ comprimento $(\mathrm{cm})$, e balança analítica com precisão de três casas decimais para determinar o peso (g) da espiga e grãos de milho.

Para a análise dos dados foi realizada a análise de variância em parcela subdividida para cada ambiente separadamente, e quando verificado efeito significativo para $1 \%$ de probabilidade pelo teste $\mathrm{F}$ aplicou-se a comparação de médias por meio do teste de Scott-Knott, utilizou-se o software Sisvar versão 5.6.

\section{Resultados e Discussão}

Na Tabela 1 apresenta-se o resumo da análise de variância - ANOVA ( por meio dos cálculos do Quadrado Médio QM e do teste F) para 5 características: MVESP (Massa verde média de espiga sem palha - g), CEVSP ( Comprimento médio de espiga verde sem palha - cm), DEVSP ( Diâmetro médio de espiga verde sem palha - cm), MGV ( Massa verde de grãos média da espiga - g) e 5 - RG (Rendimento dos grãos - \%), sob 4 ambientes (ambiente 1 = plantio em dezembro de 2018 em Palmas - TO; ambiente 2 = plantio em dezembro de 2018 em Paraiso - TO; ambiente 3 = plantio em janeiro de 2019 em Palmas - TO e ambiente 4 = plantio em janeiro de 2019 em Paraiso - TO). 
Tabela 1. Resumo da Análise de Variância de MVESP, CEVSP, DEVSP, MGV e RG para as 4 cultivares de milho com dois níveis de nitrogênio, sob 4 ambientes.

\begin{tabular}{|c|c|c|c|c|c|c|c|c|c|c|c|c|c|}
\hline \multirow[b]{2}{*}{ FV } & \multirow[b]{2}{*}{ GL } & \multicolumn{7}{|c|}{ QM (Palmas - TO) } & \multicolumn{5}{|c|}{ QM (Paraíso - TO) } \\
\hline & & \multirow{4}{*}{ 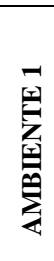 } & MVESP & CEVSP & DEVSP & MGV & RG & \multirow{4}{*}{$\sum_{\substack{|c| \\
|c|}}^{N}$} & MVESP & CEVSP & DEVSP & MGV & RG \\
\hline $\mathbf{N}$ & 1 & & $6583^{\text {ns }}$ & $4,4^{\mathrm{ns}}$ & $0,534^{\mathrm{ns}}$ & $1916^{\mathrm{ns}}$ & $9^{\mathrm{ns}}$ & & $7529^{\mathrm{ns}}$ & $7,4^{\mathrm{ns}}$ & $1,4^{\mathrm{ns}}$ & $1990^{\mathrm{ns}}$ & $84^{\mathrm{ns}}$ \\
\hline C & 3 & & $4954^{* *}$ & $8,0^{\text {ns }}$ & $0,435^{* *}$ & $3135^{* *}$ & $226 * *$ & & $5076^{* *}$ & $18,1^{\text {ns }}$ & $0,19^{\text {ns }}$ & $1729^{* *}$ & $269^{\text {ns }}$ \\
\hline \multirow[t]{3}{*}{$\mathbf{N} * \mathbf{C}$} & 3 & & $77^{\mathrm{ns}}$ & $0,1^{\mathrm{ns}}$ & $0,014^{\mathrm{ns}}$ & $55^{\mathrm{ns}}$ & $11^{\mathrm{ns}}$ & & $933^{\mathrm{ns}}$ & $1,9^{\text {ns }}$ & $0,17^{\mathrm{ns}}$ & $346^{\mathrm{ns}}$ & $129^{\text {ns }}$ \\
\hline & cv1\% & & 14,01 & 3,97 & 1,75 & 12,29 & 2,93 & & 26,84 & 6,09 & 6,38 & 29,21 & 14,49 \\
\hline & cv $2 \%$ & & 6,25 & 9,84 & 3,64 & 7,77 & 6 & & 21,64 & 6,19 & 8,87 & 29,37 & 21,72 \\
\hline FV & GL & \multirow{4}{*}{ 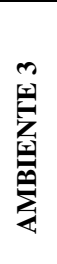 } & MVESP & CEVSP & DEVSP & MGV & RG & \multirow{4}{*}{$\frac{+}{\sum_{i=1}^{+}}$} & MVESP & CEVSP & DEVSP & MGV & RG \\
\hline $\mathbf{N}$ & 1 & & $6105^{\mathrm{ns}}$ & $1,8^{\mathrm{ns}}$ & $0,041^{\mathrm{ns}}$ & $834^{\mathrm{ns}}$ & $147^{\mathrm{ns}}$ & & $3927^{\mathrm{ns}}$ & $0,48^{\mathrm{ns}}$ & $0,31^{\mathrm{ns}}$ & $1959^{\text {ns }}$ & $67^{\mathrm{ns}}$ \\
\hline $\mathbf{C}$ & 3 & & $1926^{* *}$ & $11,1^{\mathrm{ns}}$ & $1,102 * *$ & $4072^{* *}$ & $856^{* *}$ & & $4788^{\mathrm{ns}}$ & $26,19^{* *}$ & $0,43^{\text {ns }}$ & $3530^{\mathrm{ns}}$ & $448^{* *}$ \\
\hline $\mathbf{N} * \mathbf{C}$ & 3 & & $553^{\mathrm{ns}}$ & $4,4^{\mathrm{ns}}$ & $0,282^{\mathrm{ns}}$ & $355^{\mathrm{ns}}$ & $160^{\mathrm{ns}}$ & & $656^{\mathrm{ns}}$ & $0,68^{\text {ns }}$ & $0,08^{\text {ns }}$ & $606^{\mathrm{ns}}$ & $98^{\text {ns }}$ \\
\hline & cv1\% & & 23,35 & 4,62 & 3,76 & 30,18 & 6,16 & & 25,3 & 1,93 & 6,35 & 27,63 & 11,84 \\
\hline & cv2\% & & 15,9 & 7,9 & 7,87 & 17,92 & 15,6 & & 25,16 & 6,44 & 7,6 & 35,47 & 11,37 \\
\hline
\end{tabular}

** significativo a 0,01 de probabilidade respectivamente pelo teste $\mathrm{F}$; ${ }^{\mathrm{ns}}$ não significativo Fonte: Autores.

Conforme a Tabela 1 observou-se, para cada ambiente separadamente, que há diferença significativa $(\mathrm{p}<0,01)$ apenas para a comparação entre as cultivares $(\mathrm{C} 1, \mathrm{C} 2, \mathrm{C} 3$ e $\mathrm{C} 4)$, no ambiente 1 identificou-se diferença significativa $(\mathrm{p}<0,01)$ para as características MVESP (Massa verde média de uma espiga sem palha - g), DEVSP (Diâmetro médio de uma espiga verde sem palha - cm), MGV (Massa verde de grãos média da espiga - g) e RG (Rendimento dos grãos - \%). Para o ambiente 2, observou-se as diferenças significativas para as características MVESP e MGV. Também pode-se observar que em todos os ambientes o nitrogênio, aplicado na adubação em cobertura, não promoveu diferença significativa ( $\mathrm{p}<0,01)$. Este fator pode ter ocorrido devido a influência dos genótipos dos grãos de milho verde e doce, a disponibilidade de nutrientes e as condições climáticas durante a etapa de enchimento dos grãos.

No ambiente 3 obtiveram diferença significativa $(\mathrm{p}<0,01)$ para as mesmas características avaliadas no ambiente 1 , assim nota-se que os plantios realizados em Palmas - TO apresentam comportamentos semelhantes mesmo em períodos diferentes de plantio (dezembro e janeiro).

Já o ambiente 4, as características CEVSP e RG apresentaram diferença significativa ( $<<0,01)$, diferenciando do ambiente 2, cujas características distintas foram: MVESP, MGV e RG. Nota-se que os plantios realizados em Paraiso do TO tiveram comportamentos distintos, podendo ser influenciado pelas condições climáticas (período de chuva).

Na Tabela 1, calculou-se dois coeficientes de variação - CV (\%), quantificação do erro experimental, devido ao delineamento em sub-parcela, o qual o coeficiente de variação da sub-parcela e da parcela demonstraram confiabilidade dos dados tendo valores inferiores a 30\% em sua maioria, sendo que apenas dois superiores a 30\% (30,18 e 35,47) para a característica MGV para o ambiente 3 e 4, entre os valores de coeficientes de variação. Observou-se que os milhos cultivados em Paraiso do TO tiveram um CV maior devido a maior diferença entre os grãos, desde o comprimento médio de espiga verde 
sem palha até o rendimento e segundo Fritsche-Neto et al. (2012), a classificação do CV para os experimentos com cultivo de milho varia depende das características avaliadas no estudo.

$\mathrm{Na}$ Tabela 2 compara-se os valores médias da massa verde de espiga sem palha $-\mathrm{g}$ para as cultivares $(\mathrm{C} 1, \mathrm{C} 2$ e C3 = milho verde e C4 = milho doce) nos 4 ambientes com os 2 níveis de adubação de cobertura (40 e 120 kg.ha-1 $)$.

Tabela 2. Comparação dos valores médios da massa verde de espiga sem palha (g), para as cultivares de milho verde e milho doce para os 4 ambientes.

\begin{tabular}{|c|c|c|c|c|c|c|c|c|c|c|c|c|}
\hline \multirow{2}{*}{$\begin{array}{c}\text { MVESP } \\
\text { (g) } \\
\text { Cultivar }\end{array}$} & \multicolumn{3}{|c|}{ Ambiente 1} & \multicolumn{3}{|c|}{ Ambiente 2} & \multicolumn{3}{|c|}{ Ambiente 3} & \multicolumn{3}{|c|}{ Ambiente 4} \\
\hline & $40 N$ & $120 \mathrm{~N}$ & Média* & $40 N$ & $120 \mathrm{~N}$ & Média* & $40 N$ & $120 N$ & Média* & $40 N$ & $120 \mathrm{~N}$ & Média* \\
\hline C1 & 194 & 220 & $207^{\mathrm{a}}$ & 107 & 137 & $122^{\mathrm{b}}$ & 127 & 178 & $153^{\mathrm{a}}$ & 126 & 166 & $146^{\mathrm{a}}$ \\
\hline $\mathrm{C3}$ & 165 & 207 & $186^{\mathrm{b}}$ & 131 & 190 & $160^{\mathrm{a}}$ & 151 & 162 & $156^{\mathrm{a}}$ & 161 & 175 & $167^{\mathrm{a}}$ \\
\hline C4 & 181 & 217 & $199^{\mathrm{a}}$ & 103 & 154 & $128^{b}$ & 143 & 165 & $154^{\mathrm{a}}$ & 120 & 166 & $143^{\mathrm{a}}$ \\
\hline $\mathrm{C2}$ & 128 & 157 & $143^{c}$ & 88 & 90 & $89^{c}$ & 96 & 141 & $119^{\mathrm{b}}$ & 99 & 101 & $100^{\mathrm{b}}$ \\
\hline Média** & $167 \mathrm{~A}$ & $200 \mathrm{~A}$ & 184,1 & $107 \mathrm{~A}$ & $143 \mathrm{~A}$ & 125 & $129 \mathrm{~A}$ & $161 \mathrm{~A}$ & 145 & $126 \mathrm{~A}$ & $152 \mathrm{~A}$ & 139 \\
\hline
\end{tabular}

**Médias seguidas de mesma letra não diferem entre si pelo teste de Scott-Knott, ao nível de 0,05 de probabilidade. *Letras minúsculas para a comparação na coluna (entre cultivares) e **letras maiúsculas para comparação entre os níveis de adubação de cobertura na mesma característica (ambiente).

Fonte: Autores.

Na Tabela 2, observa-se que em todos os ambientes não houve diferença significativa $(\mathrm{p}<0,05)$ pelo teste de $S c o t t$ -

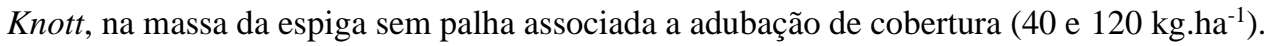

No ambiente 1, observou-se que o milho doce se assemelhou da cultivar $\mathrm{C} 1$, com os valores médios da massa verde de espiga sem palha entre 199g e 207g. E no ambiente 2, a cultivar C3 obteve um maior valor do MVESP quando comparado com as demais, sendo que esta característica pode contribuir para a produtividade do milho verde. Para os ambientes 3 e 4 as cultivares $\mathrm{C}$ 1, C3 e C4 apresentaram semelhança para a massa da espiga sem palha, mostrando que o cultivo de milho doce se assemelhou do milho verde nas cidades de Palmas - TO e Paraiso - TO. Já a cultivar de milho verde C2 obteve os valores médios de MVESP inferiores em todos os ambientes avaliados.

Segundo Perfeito et al. (2017), o milho doce cultivado sob irrigação em Urutaí - GO obteve a massa das espigas sem palha de 218 g a 242 g; já os resultados do milho doce (C4) produzido neste experimento no ambiente 1 - Palmas TO foi um peso médio de $199 \mathrm{~g}$.

O peso médio da massa verde da espiga sem palha da C1 no ambiente 1 (Tabela 2) foi de $207 \mathrm{~g}$, assemelhando-se dos dados obtidos para os milhos verdes cultivados em Goiás, com peso das espigas sem palha de $200 \mathrm{~g}$ a $254 \mathrm{~g}$ (Couto et al., 2017), indicando-se a possibilidade da produção de milho verde no Tocantins com rendimento de MVESP semelhante ao produzido no estado de Goiás.

Na Tabela 3 compara-se os valores médias do comprimento da espiga verde sem palha - cm para as cultivares (C1, C2 e C3 e C4) nos 4 ambientes com os 2 níveis de adubação de cobertura. 
Tabela 3. Comparação dos valores médios do comprimento da espiga verde sem palha - cm, para as cultivares de milho verde e milho doce para os 4 ambientes

\begin{tabular}{ccccccccccccc}
\hline CEVSP (cm) & \multicolumn{3}{c}{ Ambiente 1 } & \multicolumn{3}{c}{ Ambiente 2 } & \multicolumn{3}{c}{ Ambiente 3 } & \multicolumn{3}{c}{ Ambiente 4 } \\
\hline Cultivar & $\mathbf{4 0 N}$ & $\mathbf{1 2 0 N}$ & Média* $^{*}$ & $\mathbf{4 0 N}$ & $\mathbf{1 2 0 N}$ & Média* & $\mathbf{4 0 N}$ & $\mathbf{1 2 0 N}$ & Média* $^{*}$ & $\mathbf{4 0 N}$ & $\mathbf{1 2 0 N}$ & Média* $^{*}$ \\
& & & & & & & & & & & & \\
\hline C1 & 15,6 & 16,5 & $16,0^{\mathrm{a}}$ & 15,5 & 16,0 & $16,0^{\mathrm{a}}$ & 15,5 & 14,8 & $15,0^{\mathrm{a}}$ & 15 & 15,1 & $15,2^{\mathrm{a}}$ \\
$\mathbf{C 3}$ & 15,1 & 15,6 & $15,4^{\mathrm{a}}$ & 14,0 & 14,5 & $14,3^{\mathrm{b}}$ & 12,2 & 15,2 & $14,0^{\mathrm{b}}$ & 14,5 & 14,3 & $14,4^{\mathrm{a}}$ \\
$\mathbf{C 4}$ & 13,0 & 13,8 & $13,4^{\mathrm{a}}$ & 10,0 & 13,0 & $12,0^{\mathrm{c}}$ & 13,0 & 12,5 & $13,0^{\mathrm{c}}$ & 13,7 & 13,2 & $13,5^{\mathrm{b}}$ \\
$\mathbf{C 2}$ & 13,8 & 15,0 & $14,4^{\mathrm{a}}$ & 12,0 & 13,2 & $13,0^{\mathrm{c}}$ & 11,8 & 12,2 & $12,0^{\mathrm{c}}$ & 10,9 & 9,9 & $10,4^{\mathrm{c}}$ \\
\hline Média** & $14,0 \mathrm{~A}$ & $15,0 \mathrm{~A}$ & 14,8 & $13,0 \mathrm{~A}$ & $14,2 \mathrm{~A}$ & 14 & $13,1 \mathrm{~A}$ & $13,7 \mathrm{~A}$ & 13 & $13,5 \mathrm{~A}$ & $13,0 \mathrm{~A}$ & 13,3 \\
\hline
\end{tabular}

\footnotetext{
**Médias seguidas de mesma letra não diferem entre si pelo teste de Scott-Knott, ao nível de 0,05 de probabilidade. *Letras minúsculas para a comparação na coluna (entre cultivares) e **letras maiúsculas para comparação entre os níveis de adubação de cobertura na mesma característica (ambiente).

Fonte: Autores.
}

$\mathrm{Na}$ Tabela 3, observa-se que não houve diferença significativa $(\mathrm{p}<0,05)$, pelo teste de Scott-Knott, entre os comprimentos médios da espiga verde sem palha para os diferentes níveis de adubação de cobertura em todos ambientes. No ambiente 1 as 4 cultivares não obtiveram diferenças significativas, com comprimento médio de $14,8 \mathrm{~cm}$. No ambiente 2 e 3 , a cultivar $\mathrm{C} 1$ apresentou o maior valor médio em relação as demais, com $16 \mathrm{~cm}$ e $15 \mathrm{~cm}$ de comprimento, respectivamente.

Segundo De Lima et al. (2019), o comprimento de espiga cultivados em Jataí - GO não apresentou diferença significativa $(\mathrm{p}<0,05)$ entre as cultivares de milho verde, tendo comprimentos médios de $16,57 \mathrm{~cm}$, o qual assemelha-se com os comprimentos médios obtidos para a $\mathrm{C} 1$ no ambiente 1 e 2, com valores médios de $16 \mathrm{~cm}$. Esta característica tem uma relevância comercial, pois segundo Paiva Junior et al. (2001), o milho in natura verde comercializado em bandejas deve ter um comprimento da espiga sem palha maior de $15 \mathrm{~cm}$ e de diâmetro superior a $4 \mathrm{~cm}$. Segundo Regitano-d'arce, Fillet Spoto \& Castellucci (2015) o milho doce é comumente aplicado na comercialização de enlatados, não há indicação de cumprimento da espiga do milho doce para a venda em bandejas. Mas o diâmetro da espiga pode influenciar o rendimento dos grãos, contribuindo para a maior produção.

$\mathrm{Na}$ Tabela 4 demonstra os valores médios do diâmetro da espiga verde sem palha - cm, para as cultivares $(\mathrm{C} 1, \mathrm{C} 2$ e C3 e C4) nos 4 ambientes com os 2 níveis de adubação de cobertura. 
Tabela 4. Comparação dos valores médios do diâmetro da espiga verde sem palha - cm, para as cultivares de milho verde e milho doce para os 4 ambientes.

\begin{tabular}{|c|c|c|c|c|c|c|c|c|c|c|c|c|}
\hline \multirow{2}{*}{$\begin{array}{c}\text { DEVSP (mm) } \\
\text { Cultivar }\end{array}$} & \multicolumn{3}{|c|}{ Ambiente 1} & \multicolumn{3}{|c|}{ Ambiente 2} & \multicolumn{3}{|c|}{ Ambiente 3} & \multicolumn{3}{|c|}{ Ambiente 4} \\
\hline & $40 \mathrm{~N}$ & $120 \mathrm{~N}$ & Média* & $40 \mathrm{~N}$ & $120 \mathrm{~N}$ & Média* & $40 N$ & $120 \mathrm{~N}$ & Média* & $40 \mathrm{~N}$ & $120 \mathrm{~N}$ & Média* \\
\hline C1 & 4,7 & 5,0 & $5,0^{\mathrm{a}}$ & 3,8 & 4,3 & $4,0^{\mathrm{a}}$ & 4,6 & 4,7 & $4,7^{b}$ & 4,4 & 4,7 & $4,5^{\mathrm{a}}$ \\
\hline $\mathrm{C3}$ & 4,7 & 5,0 & $4,8^{\mathrm{a}}$ & 4,2 & 4,2 & $4,2^{\mathrm{a}}$ & 5,1 & 5,3 & $5,2^{\mathrm{a}}$ & 4,8 & 4,8 & $4,8^{\mathrm{a}}$ \\
\hline $\mathrm{C} 4$ & 4,2 & 4,6 & $4,4^{\mathrm{b}}$ & 3,5 & 4,3 & $4,0^{\mathrm{a}}$ & 4,3 & 4,5 & $4,4^{\mathrm{b}}$ & 4,0 & 4,4 & $4,1^{\mathrm{a}}$ \\
\hline $\mathrm{C} 2$ & 4,4 & 4,5 & $4,5^{\mathrm{b}}$ & 3,6 & 4,2 & $3,8^{\mathrm{a}}$ & 4,6 & 3,9 & $4,2^{\mathrm{b}}$ & 4,4 & 4,4 & $4,4^{\mathrm{a}}$ \\
\hline Média*** & $4,5 \mathrm{~A}$ & $4,8 \mathrm{~A}$ & 4,6 & $3,8 \mathrm{~A}$ & $4,2 \mathrm{~A}$ & 4 & $4,7 \mathrm{~A}$ & $4,6 \mathrm{~A}$ & 4,6 & $4,4 \mathrm{~A}$ & $4,6 \mathrm{~A}$ & 4,4 \\
\hline
\end{tabular}

**Médias seguidas de mesma letra não diferem entre si pelo teste de Scott-Knott, ao nível de 0,05 de probabilidade. *Letras minúsculas para a comparação na coluna (entre cultivares) e **letras maiúsculas para comparação entre os níveis de adubação de cobertura na mesma característica (ambiente).

Fonte: Autores.

Conforme a Tabela 4, notou-se que não há diferença significativa $(\mathrm{p}<0,05)$, pelo teste de Scott-Knott, para os diferentes níveis de adubação. Nos ambientes 2 e 4 também não se identificou diferença entre os diâmetros médios para as 4 cultivares de milho, mesmo sendo plantios realizados em Paraiso do TO em períodos distintos, as condições climáticas não influenciaram no DEVSP. Já para o ambiente 1, as cultivares de milho verde C1 e C3 apresentaram semelhança em relação a este diâmetro médio. E no ambiente 3 a cultivar C3 apresentou maior diâmetro e o milho doce assemelhou-se com as demais cultivares, com diâmetro médio de $4,4 \mathrm{~cm}$.

Segundo de Lima et al. (2019), não houve diferença significativa ( $<<0,05)$ para o diâmetro das espigas sem palha de milho verde com valores médios entre 4,26 e 4,55 cm. Já a cultivar C1 e C3, no ambiente 1, obtiveram diâmetro médio entre 4,8 e $5 \mathrm{~cm}$. Desta forma observou-se que os plantios realizados em Palmas - TO apresentaram resultados superiores e as condições climáticas não influenciaram significativamente no DEVSP, esta característica contribui para um maior rendimento na produção, demonstrando a possibilidade de cultivar o milho verde no Tocantins em períodos distintos de plantio.

O milho doce cultivado em Urutaí - GO obteve um diâmetro médio que variou entre 4,35 e 4,70 cm (Perfeito et al., 2017), assemelhando-se com os resultados obtidos pela C4 nos ambientes 1 e 3, com 4,4 cm para ambos os ambientes.

$\mathrm{Na}$ Tabela 5 apresenta os valores médios da massa verde dos grãos de 1 espiga /planta - g, para as cultivares (C1, C2 e C3 = milho verde e C4 = milho doce) nos 4 ambientes com os 2 níveis de adubação de cobertura $(40$ e 120 kg.ha-1). 
Tabela 5. Comparação dos valores médios da massa verde dos grãos da espiga-g, para as cultivares de milho verde e milho doce para os 4 ambientes.

\begin{tabular}{ccccccccccccc}
\hline MG1PL (g) & \multicolumn{3}{c}{ Ambiente 1 } & \multicolumn{3}{c}{ Ambiente 2 } & \multicolumn{3}{c}{ Ambiente 3 } & \multicolumn{2}{c}{ Ambiente 4 } \\
\hline Cultivar & $\mathbf{4 0 N}$ & $\mathbf{1 2 0 N}$ & Média* & $\mathbf{4 0 N}$ & $\mathbf{1 2 0 N}$ & Média* & $\mathbf{4 0 N}$ & $\mathbf{1 2 0 N}$ & Média* $^{*}$ 40N & 120N & Média* $^{*}$ \\
\hline $\mathbf{C 1}$ & 102 & 120 & $111^{\mathrm{a}}$ & 52 & 70 & $61^{\mathrm{a}}$ & 66 & 100 & $83^{\mathrm{b}}$ & 61 & 102 & $82^{\mathrm{a}}$ \\
$\mathbf{C 3}$ & 83 & 110 & $97^{\mathrm{b}}$ & 68 & 74 & $71^{\mathrm{a}}$ & 116 & 123 & $119^{\mathrm{a}}$ & 87 & 94 & $91^{\mathrm{a}}$ \\
$\mathbf{C 4}$ & 86 & 98 & $92^{\mathrm{b}}$ & 40 & 80 & $60^{\mathrm{a}}$ & 88 & 93 & $90^{\mathrm{b}}$ & 57 & 85 & $71^{\mathrm{a}}$ \\
$\mathbf{C 2}$ & 49 & 65 & $57^{\mathrm{c}}$ & 27 & 36 & $31^{\mathrm{b}}$ & 56 & 56 & $56^{\mathrm{c}}$ & 37 & 34 & $35^{\mathrm{b}}$ \\
\hline Média** & $80 \mathrm{~A}$ & $98 \mathrm{~A}$ & 89 & $47 \mathrm{~A}$ & $65 \mathrm{~A}$ & 56 & $81 \mathrm{~A}$ & $93 \mathrm{~A}$ & 87 & $61 \mathrm{~A}$ & $79 \mathrm{~A}$ & 70 \\
\hline
\end{tabular}

**Médias seguidas de mesma letra não diferem entre si pelo teste de Scott-Knott, ao nível de 0,05 de probabilidade. *Letras minúsculas para a comparação na coluna (entre cultivares) e **letras maiúsculas para comparação entre os níveis de adubação de cobertura na mesma característica (ambiente).

Fonte: Autores.

Na Tabela 5 verificou-se que no ambiente 1, a C1 teve a maior massa de grãos em relação as demais cultivares, já no ambiente 3 a cultivar 3 se destacou com 119 g de massa de grãos. Os ambientes 2 e 4, o milho doce apresentou semelhança ( $\mathrm{p}<0,05)$, pelo teste de Scott-Knott, na massa dos grãos quando comparado com as cultivares de milho verde (C1 e C3), sendo de 60 e 71 g de massa dos grãos, para os respectivos ambientes. Desta forma observou-se que a possibilidade de se produzir milho doce no estado do Tocantins, pois apresentou massa verde dos grãos semelhante em alguns ambientes.

Em todos os ambientes a massa dos grãos do $\mathrm{C} 2$ possuiu valores médios inferiores quando comparado com as demais cultivares, sendo que esta cultivar de milho verde não se adaptou em nenhum dos ambientes, fatores que podem ser influenciados pelo genótipo da semente, condições climáticas entre outros.

Na Tabela 6 apresenta os valores médios do rendimento dos grãos em \%, para as C1, C2, C3 e C4 nos 4 ambientes com os 2 níveis de adubação de cobertura.

Tabela 6. Comparação dos valores médios do rendimento dos grãos verdes - \%, para as cultivares de milho verde e milho doce para os 4 ambientes.

\begin{tabular}{|c|c|c|c|c|c|c|c|c|c|c|c|c|}
\hline \multirow{2}{*}{$\begin{array}{l}\text { RG (\%)) } \\
\text { Cultivar }\end{array}$} & \multicolumn{3}{|c|}{ Ambiente 1} & \multicolumn{3}{|c|}{ Ambiente 2} & \multicolumn{3}{|c|}{ Ambiente 3} & \multicolumn{3}{|c|}{ Ambiente 4} \\
\hline & $40 N$ & $120 \mathrm{~N}$ & Média* & $40 N$ & $120 \mathrm{~N}$ & Média* & $40 N$ & $120 \mathrm{~N}$ & Média* & $40 N$ & $120 \mathrm{~N}$ & Média* \\
\hline C1 & 52 & 55 & $53^{a}$ & 47 & 51 & $49^{a}$ & 52 & 56 & $54^{\mathrm{b}}$ & 47 & 61 & $54^{\mathrm{a}}$ \\
\hline C3 & 51 & 53 & $51^{\mathrm{a}}$ & 51 & 42 & $47^{\mathrm{a}}$ & 76 & 77 & $77^{\mathrm{a}}$ & 53 & 53 & $53^{\mathrm{a}}$ \\
\hline C4 & 48 & 45 & $46^{\mathrm{b}}$ & 40 & 52 & $46^{\mathrm{a}}$ & 63 & 57 & $60^{\mathrm{b}}$ & 47 & 51 & $49^{\mathrm{a}}$ \\
\hline $\mathrm{C2}$ & 38 & 41 & $40^{c}$ & 30 & 38 & $34^{\mathrm{b}}$ & 58 & 40 & $49^{\mathrm{b}}$ & 38 & 33 & $35^{\mathrm{b}}$ \\
\hline Média** & $47 \mathrm{~A}$ & $49 \mathrm{~A}$ & 48 & $42 \mathrm{~A}$ & $46 \mathrm{~A}$ & 44 & $62 \mathrm{~A}$ & $57 \mathrm{~A}$ & 60 & $46 \mathrm{~A}$ & $49 \mathrm{~A}$ & 48 \\
\hline
\end{tabular}

**Médias seguidas de mesma letra não diferem entre si pelo teste de Scott-Knott, ao nível de 0,05 de probabilidade. *Letras minúsculas para a comparação na coluna (entre cultivares) e **letras maiúsculas para comparação entre os níveis de adubação de cobertura na mesma característica (ambiente).

Fonte: Autores. 
Na Tabela 6, os rendimentos de grãos verdes da cultivar C4 foram semelhantes ( $<<0,05)$, pelo teste de Scott-Knott, com as cultivares $\mathrm{C} 1$ e $\mathrm{C} 3$ nos ambientes 2 e 4 . Já nos ambientes 1 a cultivar $\mathrm{C} 1$ assemelhou-se com a cultivar C3, e no ambiente 3 a cultivar C3 teve um maior rendimento de 77\%. Observa-se que o milho doce cultivado em Palmas - TO apresentou um rendimento de grãos verdes de $60 \%$, semelhante a $\mathrm{C} 1$, desta forma nota-se que mesmo em condições climáticas distintas e genótipos de milho diferentes, o milho doce apresentou um rendimento significativo, possibilitando o estudo do cultivo de milho doce na Região Norte do Brasil.

De acordo com Gundim et al. (2019), para o experimento realizado com milhos verdes produzidos no Acre, plantio com espaçamento de $0,75 \mathrm{~m}$ e $1 \mathrm{~m}$ de comprimento, obtiveram um rendimento médio dos grãos leitosos de aproximadamente 70\%, sendo que as cultivares $\mathrm{C} 1$ e C3 alcançaram médias superiores (54\% e 77\%) para o ambiente 3.

Segundo Cruz (2014) o rendimento de grãos para o milho doce cultivado com irrigação não obteve diferença significativa $(\mathrm{p}<0,05)$ em relação as doses e formas de parcelamento de $\mathrm{N}$, porém a massa de grãos apresentou correlação positiva com a massa das espigas, promovendo alteração semelhante entre a quantidade da massa de grãos e com a massa das espigas. Neste estudo para as doses de zero a $300 \mathrm{~kg} \cdot \mathrm{ha}^{-1} \mathrm{de} \mathrm{N}$, o rendimento de grãos variou de 47,1 a 56,9\%, assemelhandose com os resultados obtidos para o milho doce cultivada nos ambientes 4 ambientes, cujos valores médios do rendimento dos grãos variaram entre 46 a $60 \%$.

Avaliar o rendimento médio dos grãos de milho é um parâmetro importante para o processo produtivo, pois a escolha de uma determinada cultivar pode contribuir para a maior rentabilidade econômica no processamento industrial.

\section{Considerações Finais}

Este estudo possibilitou a comparação dos rendimentos das cultivares de milho verde e milho doce, cultivados em Palmas - TO e Paraíso do TO, para o consumo in natura, observou-se que as características físicas de comprimento, diâmetro, massa das espigas sem palha e massa dos grãos podem ser influenciadas pelos diferentes ambientes, épocas de semeadura e fatores genótipos das cultivares do milho.

Desta forma foi importante realizar este levantamento agronômico do milho verde e do milho doce "in natura", pois possibilitou a avaliação e comparação das características do milho doce cultivado no Estado do Tocantins.

Como sugestão para trabalhos futuros seria proposto avaliar mais uma cultivar de milho doce e inserir adubação de nitrogênio em dosagens distintas.

\section{Referências}

Companhia Nacional de Abastecimento. (2020). Acompanhamento da Safra Brasileira: $8^{\circ}$ Levantamento de grãos. SAFRA 2020. Brasília: CONAB, 2020.

Couto, C. A., et al. (2017). Desempenho de Cultivares de Milho Destinados para Produção de Milho Verde e Silagem. Journal of Social, Technological and Environmental Science. http://dx.doi.org/10.21664/2238-8869.2017v6i1.p232-251.

Cruz, C. A. (2014). Produtividade e rendimento industrial do milho doce irrigado em função de dose e parcelamento de nitrogênio. 68 p. Dissertação (mestrado) - Universidade Estadual Paulista Júlio de Mesquita Filho, Faculdade de Ciências Agrárias e Veterinárias.

de Lima, N. G., et al. (2019). Avaliação de cultivares de milho para consumo in natura em Jataí - GO. Caderno de ciências agrárias. Agrarian Sciences Journal. Universidade Federal de Minas Gerais.

Empresa Brasileira de Pesquisa Agropecuária. (2016). Época de plantio e cultivares de milho safrinha no Tocantins. Palmas, TO: Embrapa Pesca e Aquicultura.

Fritsche-neto, R., et. al. (2012). Updating the ranking of the coefficients of variation from maize experiments. Acta Scientiarum, Maringá. http://dx.doi.org/10.4025/actasciagron.v34i1.13115.

Gil, A.C. (1994). Métodos e técnicas de pesquisa social (4a ed.). Atlas. 
Research, Society and Development, v. 10, n. 3, e11910313082, 2021

(CC BY 4.0) | ISSN 2525-3409 | DOI: http://dx.doi.org/10.33448/rsd-v10i3.13082

Giordano, D., et al. (2018). Influence of Agricultural Management on Phytochemicals of Colored Corn Genotypes (Zea mays L.). Part 1: Nitrogen Fertilization. J. Agric. Food Chem.

Gundim, A. S. (2019). Produtividade do milho verde irrigado por gotejamento na amazônia ocidental. Enciclopédia biosfera. http://dx.doi.org/10.18677/EnciBio_2019A110.

Martin, T. N., et al. (2011). Perfil do manejo da cultura de milho no sudoeste do Paraná. Revistas Científicas de América Latina y el Caribe, Espanã y Portugal. http://dx.doi.org/10.1590/S0034-737X2011000100001.

Nascimento, F. N. (2017). Desempenho da produtividade de espigas de milho verde sob diferentes regimes hídricos. Revista Brasileira de Milho e Sorgo. http://dx.doi.org/10.18512/1980-6477.

Paiva Junior, M. C., et al. (2001). Desempenho de cultivares para a produção de milho verde em diferentes épocas e densidades de semeadura em Lavras MG. Ciência e Agrotecnologia, Lavras.

Perfeito, D. G. A., et al. (2017). Caracterização pós-colheita de milho doce submetido ao parcelamento de fertirrigação nitrogenada. Braz. J. Food Technol. Campinas. http://dx.doi.org/10.1590/1981-6723.14016.

Regitano-d'arce, M. A. B., Fillet Spoto, M. H., \& Castellucci, A. C. L. (2015). Processamento e industrialização do milho para alimentação humana. Visão agrícola.

Santos, D. S. (2018). Composição centesimal de milho Crioulo coletado em localidades do estado da Paraíba. Revista Verde de Agroecologia e Desenvolvimento Sustentável. http://dx.doi.org/10.18378/rvads.v13i3.5628.

Xiaotong, G., et al. (2018). Genetic Engineering of Maize (Zea mays L.) with Improved Grain Nutrients. J. Agric. Food Chem. 10.1021/acs.jafc.7b05390. 